\title{
EL PRINCIPIO DE DIGNIDAD DE LA PERSONA HUMANA EN LA TEORÍA KANTIANA: ALGUNAS CONTRADICCIONES
}

\author{
NURIA BELLOSO MARTÍN*
}

\begin{abstract}
RESUMO: Este artigo analisa o princípio da dignidade da pessoa humana sob a perspectiva das obras de Kant propondo uma atualização crítica do conceito de dignidade humana derivado da doutrina kantiana. Destaca, ainda, a aplicação do princípio da dignidade da pessoa humana como orientador do ordenamento jurídico no direito constitucional espanhol e no direito europeu.
\end{abstract}

PALAVRAS-CHAVE: Dignidade, Pessoa Humana, Razão, Moral e Liberdade.

ABSTRACT: This article analyzes the principle of human dignity from the perspective of Kant's works proposing a critical update of the concept of human dignity derived from the Kantian doctrine. In addition, highlights the application of the human dignity's principle as the guide in Spanish constitutional law and European law.

KEYWORDS: Dignity, Human Person, Reason, Moral and Freedom.

SUMÁRIO: 1. Introdução; 2. A doutrina e da filosofia kantiana da dignidade da pessoa humana; 3. A dignidade da pessoa humana nos Fundamentos da metafísica dos costumes; 4. A dignidade da pessoa na Metafísica da moral; 5. Conveniência de uma releitura crítica do pensamento de Kant sobre a dignidade da pessoa humana; 6. O princípio da dignidade da pessoa humana e na sua realização como a atual doutrina.

SUMMARY: 1. Introduction; 2. The doctrine and the Kantian philosophy of human dignity; 3 . The dignity of the human person in the Grounds of the metaphysics of morals; 4. The dignity of the person in the Metaphysics of morals; 5 . Convenience of a critical rereading of Kant's thinking about the dignity of the human person; 6 . The principle of human dignity and its realization as the current doctrine.

SUMARIO: 1. Introducción; 2. La doctrina y el ideario Kantiano de la dignidad humana; 3. La dignidad de la persona humana en la fundamentación de la metafísica de las costumbres; 4. La dignidad de la persona en la metafísica de las costumbres. Algunas contradicciones con la fundamentación de la metafísica de las costumbres; 5. Conveniencia de una relectura crítica del pensamiento de Kant acerca de la dignidad de la persona humana; 6. El principio de dignidad de la persona humana y su concreción según la doctrina actual.

\footnotetext{
* Nuria Belloso Martín es Profesora Titular de Filosofía del Derecho en la Facultad de Derecho de la Universidad de Burgos (España). Es Coordinadora del Programa de Doctorado del Departamento de Derecho Público "Sociedad plural y nuevos retos del Derecho". Es Directora del Curso de Especialista Universitario en Mediación Familiar. Colabora en Cursos de Mestrado y Doctorado en diversas universidades brasileñas. Participa en varios Programas de Investigación -CNpQ.
} 


\section{INTRODUCCIÓN}

La idea de dignidad nos remite a considerar que cada ser humano tiene en sí algo intrínsecamente valioso, que le dota de unas especiales características y que, incluso en situaciones precarias, lo sigue conservando. Es algo no negociable, ni disponible ni por el propio sujeto ni por el poder político. Y sobre todo se pone de manifiesto cuando hay conductas que atentan contra esa dignidad, innata al hombre y que no poseen las demás criaturas.

La dignidad de la persona humana resulta difícil de definir y conceptuar. De ahí que vayamos a utilizar dos dimensiones para poder ofrecer una caracterización básica de la misma: la primera va a ser la dimensión histórica deteniéndonos concretamente, en la formulación kantiana acerca de la dignidad, que fue quien inauguró una sistematización sobre este principio; en segundo lugar, haremos referencia al marco de los derechos humanos, como aquellos que permiten configurar una delimitación jurídica -ya no sólo moral- de la dignidad de la persona, al poner en relación los derechos fundamentales con lo que es su fundamento: la dignidad.

Una de las primeras cuestiones a dilucidar que se nos presenta es la relativa a su concepto: ¿qué es la dignidad humana? ${ }^{1}$ Es un término que resulta familiar a todos, incluso a los no versados en derecho. La referencia al principio de dignidad puede encontrarse en el área jurídica, así como también en la religiosa, la antropológica, la ética y la política. De ahí deriva su dificultad, pues rebasa el campo estrictamente jurídico para colocarse como un "comodín” del que podemos servirnos para justificar conductas y para reclamar comportamientos. La dificultad de su concepto no se circunscribe a los diversos campos en que se pueda aplicar sino también, como ha señalado J. González Pérez que "en nombre de la dignidad se llegue a soluciones

\footnotetext{
${ }^{1}$ En relación a los diversos significados del término dignidad, vid. PÉREZ TRIVIÑO, J.L., La letra escarlata, Colección CineDerecho, Valencia, tirant lo blanch, 2003, espec. pp. 57-60. También se ocupa de la dignidad en I. Kant (pp. 71-76).

Generalmente, en los últimos años se ha atribuido a la dignidad el significado de la imposibilidad de tratar a quien lo posee únicamente como un medio y no como un fin en sí mismo. Algunas definiciones en la doctrina española han optado por esta perspectiva. Así, por ejemplo, E. Fernández define la dignidad como "el valor de cada persona, el respeto mínimo a su condición de ser humano, respeto que impide que su vida o su integridad sea sustituida por otro valor social” (Cfr. FERNÁNDEZ, E., Dignidad humana y ciudadanía cosmopolita, Madrid, Instituto de Derechos Humanos Bartolomé de las Casas, Universidad Carlos III-Dykinson, 2001, p. 20); Peces Barba la califica como "el valor intrínseco de la persona, derivado de una serie de rasgos que la hacen única e irrepetible, que es el centro del mundo y que está centrada en el mundo" (PECESBARBA MARTÍNEZ, G., La dignidad de la persona desde la Filosofía del Derecho, Madrid, DykinsonInstituto de Derechos Humanos “Bartolomé de Las Casas"-Universidad Carlos III de Madrid, 2002, p. 65); el propio Tribunal Constitucional español la ha calificado como "el valor espiritual y moral inherente a ña persona” (STC 53/1985, fundamento jurídico $8^{\circ}$ ).

Ma . L. Marín Castán subraya la doble categoría de la dignidad: a) pluridisciplinar, porque en su configuración confluyen diversas disciplinas; b) pluridimensional, por lo que siguiendo a J. Ruiz Jiménez, distingue cuatro niveles de divinidad: la dimensión religiosa -en cuya virtud se concibe al hombre a imagen y semejanza de Dios-; la dimensión ontológica -en la que se considera al hombre como ser dotado de inteligencia racional, con conciencia de sí mismo y de su superioridad en el orden de la naturaleza-; la dimensión ética en el sentido de la autonomía moral -coincidiría con el planteamiento kantiano-; la dimensión social, como estima o fama dimanante de un comportamiento valioso (MARÍN CASTÁN, Ma.L., "La dignidad humana, los derechos humanos y los derechos constitucionales”, Revista de Bioética y Derecho, $\mathrm{n}^{\circ}$ 9, enero 2007, p. 2 (http://www.bioeticayderecho.ub.es).
} 
radicalmente contrarias sobre temas fundamentales tan de nuestros días como la admisibilidad de ciertas formas de provocación y manipulaciones genéticas, el aborto, la disponibilidad de órganos humanos, los experimentos médicos con personas y la eutanasia"2. No cabe duda de que las nuevas tecnologías y los avances científicotécnicos dejan su impronta en la concepción y evolución del hombre y de sus derechos y, por lo tanto, también en el propio concepto de dignidad de la persona humana en la actualidad, tema al que nos referiremos más adelante.

Una segunda cuestión sería la relativa de dónde proviene la noción de dignidad de la persona. El Profesor G. Peces-Barba Martínez ha trabajado ampliamente el tema de la dignidad de la persona y, de entre los diversos enfoques bajo los que se puede analizar la dignidad, ha prestando especial atención al histórico, al estudio del origen y desarrollo de la dignidad humana en la historia del pensamiento: desde el pensamiento antiguo y medieval, transitando por el renacimiento y la Ilustración hasta llegar a la modernidad ${ }^{3}$. Apunta que el sentido actual de dignidad humana arranca

${ }^{2}$ GONZÁLEZ PÉREZ, J., La dignidad de la persona, Madrid: Civitas, 1986, pp. 19-20.

R. Valls apunta que la discusión levantad en España acerca de la legitimidad de la eutanasia ha puesto de manifiesto que el término dignidad "cobija dos conceptos bien distintos de esa dignidad, en el fondo incompatibles. Para unos, aferrados a la concepción católica tradicional, la dignidad común a todos los seres humanos procede de su condición de hijos de Dios y reside en la capacidad de acatar y observar la ley moral, la cual de ninguna manera emana de los humanos mismos. La razón puede conocerla y de hecho la conocen -dicen- pero no la crea ni la promulga, porque el deber procede de una instancia ajena, llámese ésta Dios, finalidad de la naturaleza o como sea. Para otros, por el contrario, la dignidad humana consiste en la capacidad que tenemos los humanos de darnos ley moral a nosotros mismos. En la jerga kantiana, los primeros profesan heteronomía moral (ley de otro), mientras los segundos proclamamos la autonomía moral del ser humano (ley de uno mismo). Consiguientemente, la eutanasia es considerada inmoral por los primeros, en tanto no acata el precepto divino de no matar, mientras para los segundos es legítima una ley que la permita y, sin imponerle a nadie, por supuesto, exija garantías de plena libertad en quien la pida y en quien la lleve a cabo" (VALLS, R., "El concepto de dignidad humana", Revista de Bioética y Derecho, no 5, diciembre 2005, p. 1 ((http://www.bioeticayderecho.ub.es).

${ }^{3}$ Vid. PECES-BARBA MARTÍNEZ, G., op. cit..

Vid. también, sobre el mismo tema, GONZÁLEZ AMUCHÁSTEGUI, J., Autonomía, dignidad y

ciudadanía. Una teoría de los derechos humanos, Valencia, tirant lo blanch, 2004, p. 417 ss.

G. Peces-Barba apunta que a lo largo de la historia podemos distinguir dos concepciones de la dignidad humana: la heterónoma y la autónoma. Los rasgos de la concepción heterónoma se encuentran fuera del propio individuo (Vg. La ciudadanía romana). Se vincula al puesto o rango que ocupa la persona. Llega a nuestros días manifestándose en el dinero y la riqueza (la dignidad se mide en función de la riqueza de cada uno). La segunda, la autónoma, es la que está situada en el interior de cada persona y depende de rasgos de la concepción humana.

Desde el Renacimiento se va desgranando el concepto de dignidad humana hasta llegar a Kant que formalizará esta corriente. Somos seres que nos diferenciamos de los demás animales. Luis Vives y los gramáticos españoles que inauguran los cursos universitarios de los siglos XVI y XVII apuntan algunos: 1) Somos seres capaces de decidir o elegir (Vg. Max Scheller: "el hombre es el único animal capaz de decir 'no')”; 2) Capacidad de constituir conceptos generales y razonables: filosofía, técnica, ciencia; 3) Capacidad de comunicación y de diálogo y de crear cultura; 4) Capacidad para convivir en un sistema social con reglas sofisticadas y complejas: el derecho regula la escasez. En la abundancia no sería necesario el derecho; 5) Capacidad de buscar unos fines últimos que se vinculen a la salvación, a la felicidad: Kant formalizará esta corriente cuando formule que somos dignos porque somos seres de fines, porque no tenemos precio.

Sobre estas características podemos asentar los derechos humanos, libertad, igualdad, solidaridad, seguridad. Todos los demás derechos derivan de estos principios y desarrollan estos principios. (Conferencia pronunciada por G. Peces-Barba en el I Congreso Internacional de Derecho Humanos. La segunda controversia de Valladolid, celebrado en Valladolid, en octubre de 2006). 
del tránsito a la modernidad, donde surge el concepto de hombre centrado en el mundo y centro del mundo. Sin embargo, ya desde la antigüedad podemos encontrar materiales que servirían después para la construcción del modelo moderno de la dignidad.

Resulta común que se atribuya la primera enunciación del principio de dignidad humana al pensamiento de Inmanuel Kant. Ciertamente tal atribución deriva del hecho de que Kant ha sido uno de los primeros teóricos en reconocer que al hombre no se le puede atribuir un valor -entendido como precio-, justamente en la medida en que debe ser considerado como un fin en sí mismo y en función de su autonomía en cuanto ser racional. ${ }^{4}$

Sin embargo, el pensamiento kantiano acerca de la dignidad de la persona humana, al ser confrontado con sus concepciones acerca de las reglas del derecho, parece que no refleja con exactitud aquello que hoy se entiende como tal. Para llevar a cabo esta labor de comprensión somera del principio de dignidad en el pensamiento de Kant, vamos a tomar como referencia básica dos de sus obras, la Fundamentación de la metafísica de las costumbres $(1785)^{5}$ y la Metafísica de las costumbres $(1797)^{6}$. Concretamente, la concepción kantiana de la dignidad humana, contenida en estas dos obras, a juicio de Hoerster, y que vamos a ir analizando en estas páginas, es: la dignidad es un atributo "de un ser racional que no obedece a ninguna otra ley más que a la que él mismo se da"; "Por lo tanto, la autonomía es el fundamento de la dignidad de la naturaleza humana o de toda naturaleza racional"; "Cuando algo tiene un precio, en su lugar puede colocarse algo diferente como equivalente en cambio, aquello que está por encima de todo precio y, por lo tanto, no tiene ningún equivalente, posee dignidad”; por último, "La persona no puede ser tratada (ni por otra persona ni por sí misma) meramente como un medio sino que tiene que ser en todo momento utilizada al mismo tiempo como fin; en ello consiste su dignidad"7 .

\footnotetext{
${ }^{4}$ Alexandre dos Santos Cunha destaca la actualidad del tema y el reconocimiento que se debe a Kant por su formulación: “(...) El gran legado del pensamiento kantiano para la filosofía de los derechos humanos, con todo, es la igualdad en la atribución de dignidad. En la medida en que la libertad en el ejercicio de la razón práctica es el único requisito para que un ente se revista de dignidad, y que todos los seres humanos gozan de esa autonomía, se tiene en la condición humana el soporte fáctico necesario y suficiente para la dignidad, independientemente de cualquier tipo de reconocimiento social (SANTOS CUNHA, A. (dos), A normatividade da pessoa humana: o estudo jurídico da personalidade e o Código Civil de 2002, Rio de Janeiro, Forense, 2005, pp. 85-88).

${ }^{5}$ Citaremos tomando como referencia la edición bilingüe y traducción de J. Mardomingo, Barcelona, Ariel, 1999

${ }^{6}$ Citaremos tomando como referencia la edición de Ed. Tecnos con estudio preliminar de A. Cortina y trad. y notas de A. Cortina y J. Conill, $4^{\text {a }}$ ed., Madrid, 2005.

En el estudio preliminar, A. Cortina nos recuerda que la historia de la aparición de esta obra fue accidentada. Desde 1765 Kant anunciaba que contaba con los materiales necesarios para unos "principios metafísicos de la sabiduría cósmica práctica” pero hasta 1997 no se publica la primera edición de los principios metafísicos de la Doctrina del Derecho. Razones de un triple orden pueden apuntarse para su justificación: las dificultades en la resolución de algunos de los problemas, como es el caso del derecho de propiedad cuestión precisamente a la que vamos a hacer especial referencia-, tan polémico ya en su época; la avanzada edad del autor, y, por último, una razón de orden político como era el temor a la censura, dado que, como ya sabemos, Kant se había visto obligado a renunciar a escribir sobre filosofía de la religión (CORTINA, A., op. cit., p. XVIII-XIX).

${ }^{7}$ HOERSTER, N., “Acerca del significado del principio de la dignidad humana”, en En defensa del positivismo jurídico, trad. J. M. Seña y rev. E. Garzón Valdés y R. Zimmerling, Barcelona: Gedisa, 1992, p. 92.
} 
Es cierto que vamos a encontrar dificultades en precisar el concepto de dignidad humana a la luz de estas formulaciones kantianas y en poder objetivar su determinación. Pero si tomamos como referencia las tradiciones culturales en las que se ha utilizado el principio de dignidad humana entendido como valor de cada persona -como apunta E. Fernández García- ${ }^{8}$, la tarea se hará más simple. En este sentido, un análisis de la historia y de la fundamentación de los derechos fundamentales, entendida como el origen y la evolución de esas exigencias de la dignidad humana, puede resultar de gran ayuda. Así, a la pregunta kantiana de cuándo o en qué casos la persona es tratada como un medio, podríamos responder que cuando se atenta injustificadamente contra su autonomía, su seguridad, su libertad o su igualdad. En el mismo sentido, podríamos responder que se trata a la persona como un fin, es decir, se la reconoce su dignidad, cuando se crean normas y se establecen instituciones que fomentan el respeto y la garantía de los derechos humanos.

2. LA DOCTRINA Y EL IDEARIO KANTIANO DE LA DIGNIDAD HUMANA

Conviene partir de la premisa de que en la Fundamentación de la metafísica de las costumbres, Kant pretendió formular raciocinios en el campo de la filosofía moral, para comprender cómo los seres humanos formulan su universo axiológico, a pesar de que no esté dotado de coerción. En la obra Metafísica de las costumbres, Kant quiso demostrar cómo y porqué se deben formular preceptos jurídicos, estos sí dotados de coerción para viabilizar la convivencia social.

La distinción, aunque tenue -como veremos más adelante-, entre las dimensiones moral y jurídica en la obra de Kant se delinea claramente en las palabras de JeanLouis Bergel: “(...) Kant, negando el fundamento metafísico de todas las morales transcendentes, extrae la regla moral de la voluntad autónoma de los hombres. Así, según él, la moral deriva de la 'voz interior' de cada cual y no de un mandato exterior, en cuanto el derecho es una regla de vida trazada y aplicada bajo la coerción social. Del mismo modo, para Kant, el derecho se interesará por las acciones, por el 'fuero externo', y no por los móviles que las inspiran, a la vez que la moral sólo se concentrará en las intenciones y en los motivos del hombre, en su ‘fuero interno’ y no en sus acciones".

También existe, en el universo kantiano, una separación de carácter meramente formal entre moral y derecho, ya que esencialmente estos dos órdenes son idénticos en sus fundamentos, que se resumen en la autonomía racional. En la teoría kantiana, se procesa la separación entre derecho y moral, bajo el prisma formal y no material, es decir, la distinción depende del motivo por el cual se cumple la norma jurídica o moral.

Son varios los estudios y trabajos que se han ocupado del análisis del principio de dignidad humana en Kant y sus diversas aplicaciones. Podemos destacar: V. CAMPS, "La dignidad según Kant” en Historia, lenguaje, sociedad. Homenaje a Emilio LLedó, Barcelona, Crítica, 1989, p. 416 ss; también, J. MUGUERZA, "La alternativa del disenso", en El fundamento de los derechos humanos, edic. preparada por G. Peces-Barba, Madrid, Debate, 1989, p. 43 ss.

${ }^{8}$ Cfr. FERNÁNDEZ GARCÍA, E., Dignidad humana y ciudadanía cosmopolita, Madrid, DykinsonInstituto de Derechos Humanos “Bartolomé de Las Casas”-Universidad Carlos III de Madrid, 2001, p. 24. ${ }^{9}$ BERGEL, J.L., Teoria geral do direito, trad., Ma. E. Galvão, São Paulo, Martins Fontes, 2001, p. 48. 
En el acto moral, el acto sólo puede ser la propia idea del deber, a pesar de que sea directamente deber jurídico y solo indirectamente deber moral. Por ello, en el mismo acto jurídico, el motivo de actuar puede ser, además del motivo moral de cumplir el deber, el miedo a la sanción, ya sea una pena corporal o pecuniaria. Kant identifica el derecho con el poder de constreñir.

El criterio de distinción entre derecho y moral, según Kant, no es el de la exterioridad para el derecho y la interioridad para la moral, como habían formulado Puffendorf y Tomasio, sino el motivo por el cual se obedece la legislación: el motivo absoluto del deber por el puro deber en el caso de la legislación moral (que por lo tanto es interna) y un motivo empírico en el caso de la legislación jurídica (que por tanto es externa). Como afirma F. González Vicén, "Kant quiere distinguir, pero no separar, la moral del Derecho; más aún, todo su esfuerzo está dirigido en este punto, al contrario, a la fundamentación del cumplimiento del Derecho como un deber moral. La diferenciación de las obligaciones morales y éticas por el motivo de la acción, (...) hace referencia exclusivamente a la estructura formal de la obligación misma, sin que implique ni una inconciabilidad ni una irreductibilidad de las dos clases de obligaciones"

Como afirma Kant, todos los imperativos mandan, ya hipotética, ya categóricamente. El primero representa la necesidad práctica de una acción posible, como medio de conseguir otra cosa que se quiere. El segundo, el categórico, sería el que representase una acción por sí misma, sin referencia a ningún otro fin, como objetivamente necesaria. Si la acción es buena sólo como medio para alguna otra cosa, entonces es el imperativo hipotético. Pero si la acción es representada como buena en sí, esto es, como necesaria en una voluntad conforme con la razón, como un principio de tal voluntad, entonces es el imperativo categórico. Se trata de un imperativo que, sin poner como condición ningún propósito a obtener por medio de cierta conducta, manda esa conducta inmediatamente. Este imperativo es categórico y puede llamarse de la moralidad. "Cuando pienso en general un imperativo hipotético, no sé de antemano lo que contendrá; no lo sé hasta que la condición me es dada. Pero si pienso un imperativo categórico, ya sé el punto lo que contiene”. Según el imperativo hipotético "debo hacer algo porque quiero alguna otra cosa”; según el imperativo categórico, “debe obrar de este o del otro modo, aun cuando no quisiera otra cosa”.

En la doctrina moral de Kant puede apreciarse la influencia de la tradición griega, de mirar con prevención las inclinaciones naturales y preferir la razón, como la que debe orientar las acciones del hombre. También hay una exaltación, de tinte cristiano, en relación al valor de la persona humana, que se eleva por encima de cualquier otro ser. Esta elevación se debe a la moralidad. Todas las cosas tienen un precio, según Kant, pero el hombre no, y lo que le corresponde en lugar del precio es la dignidad.

En su obra, la Crítica de la razón pura, deja clara la relevancia de la moralidad: frente al mundo de la naturaleza, regido por la causalidad, está el mundo de la libertad, que no está vinculado a la concatenación causa y efecto, sino que decide lo

\footnotetext{
${ }^{10}$ GONZÁLEZ VICÉN, F., “Introducción” a la Introducción a la teoría del Derecho de I. Kant, trad. e introduc. de F. González Vicén, Madrid, Marcial Pons, 2005, p. 25.
} 
que ha de hacer independientemente de lo que pase en el exterior. Sólo el hombre es capaz de obrar conforme a este principio de libertad. Esta manera de entender la libertad es sinónimo de dignidad y moralidad. La libertad no puede entenderse meramente como externa, de obrar sin violencia exterior, sino que la libertad tiene que ser también interna. Cuando el motivo que dirige la acción del hombre es moral, es decir, independiente de la búsqueda de la felicidad, la acción en el exterior sigue estando sometida a la ley de la causalidad, pero el hombre, en su fuero interno, se ha liberado, porque el determinante de su actitud está fuera del orden causal, es una actitud moral.

La concepción antropológica kantiana y la influencia que ejerce en su doctrina moral se ve más claramente en la segunda fórmula con que se expresa el imperativo categórico: "Obra de tal modo que tomes a la humanidad, tanto en tu persona como en la de cualquier otro, siempre al mismo tiempo como un fin y no solamente como un medio". Esta concepción de la moralidad pone de manifiesto la influencia rousseauniana de la libertad y de la fórmula de la voluntad general, "cada uno, uniéndose a todos, no obedezca más que a sí mismo y quede tan libre como antes”. Esta segunda fórmula sirve muy bien a nuestro propósito de justificar la sistematización del principio de dignidad de la persona. Este segundo imperativo descansa, para Kant, en la convicción de que "el hombre existe como un fin en sí mismo" -lo que comúnmente se conoce en la teoría kantiana como el 'reino de los fines'-. ${ }^{11}$ García Morente destaca de la segunda formulación del imperativo kantiano precisamente que el hombre debe ser siempre considerado como hombre y no como cosa ni como objeto ${ }^{12}$.

Lo cierto es que Kant defiende una legislación universal y un reino de fines, es decir, el conjunto de seres racionales guiados por unas leyes comunes. Los deberes del derecho pueden ser solamente externos mientras que los deberes de la moral no pueden ser solamente externos sino que también son internos, puesto que la moralidad radica en el fuero interno. Por ello, la moral no puede ser coaccionada, impuesta por coacción, mientras que el derecho sí puede imponerse mediante la coacción. Por ello nos presenta Kant el derecho desde una perspectiva racional: el conjunto de las condiciones en virtud de las cuales la libertad de cada uno puede coordinarse con la libertad de los demás, según una ley general ${ }^{13}$.

\footnotetext{
${ }^{11}$ J. Muguerza, partiendo de esta segunda formulación kantiana, construye el imperativo de la disidencia. A diferencia del principio de universalización, desde el que se pretendía fundamentar la adhesión a valores como la dignidad, la libertad o la igualdad, lo que este imperativo habría de fundamentar es más bien la posibilidad de decir "no" a situaciones en las que prevalecen la indignidad, la falta de libertad o la desigualdad. Es decir, se pregunta Muguerza si tras tanta insistencia en el consenso acerca de los derechos humanos, no extraeremos más provecho de un "intento de fundamentación desde el disenso, esto es, de un intento de fundamentación 'negativa' o disensual de los derechos humanos”, a la que llamará 'la alternativa del disenso’ (MUGUERZA, J., op. cit., p. 43).

${ }^{12}$ Vid. GARCÍA MORENTE, M., y ZARAGÜETA BENGOECHEA, J., Fundamentos de Filosofía, $8^{\mathrm{a}}$ ed., Madrid, Espasa-Calpe, 1979.

${ }^{13}$ No vamos a extendernos acerca de la distinción kantiana entre el reino empírico o fenoménico y el moral o nouménico. Sin embargo, como ha apuntado J. Muguerza, conviene destacar que en Kant el sujeto moral y el sujeto empírico no coinciden exactamente, no porque sean dos sujetos distintos sino porque el sujeto moral es el sujeto en su integridad. Es decir, no se puede reducir a los individuos a su condición de sujetos empíricos: “(...) ni el peor criminal podría ser nunca reducido a su conducta observable, puesta que ésta no nos permite escrutar sus más recónditas motivaciones ni intenciones (...)” (op. cit., p. 49).
} 
En opinión de Kant, siendo el hombre racional y libre, es capaz de imponer a sí mismo normas de conducta, designadas por normas éticas, válidas para todos los seres racionales que, por su racionalidad, son fines en sí y no medios al servicio de otros. La norma básica de conducta moral que el hombre se puede prescribir es que en todo lo que haga debe siempre tratarse a sí mismo y a sus semejantes como un fin y nunca como un medio. Aplicada a la conveniencia jurídico-social, esa norma moral básica se transforma en norma de derecho natural. La obediencia del hombre a su propia voluntad libre y autónoma constituye, para Kant, la esencia de la moral y del derecho natural. Las normas jurídicas, para tal concepción, serán de derecho natural, si su obligatoriedad fuera cognoscible por la razón pura, independiente de ley externa o de derecho positivo, si dependieran, para obligar, de ley externa ${ }^{14}$. Pero, en esta hipótesis, se debe presuponer una ley natural, de orden ético, que justifique la autoridad del legislador, es decir, su derecho de obligar a otro por simple decisión de su voluntad. Tal ley natural, que es el principio de todo derecho, deriva de la libertad humana, reconocida por mediación del imperativo moral categórico. ${ }^{15}$

Sin embargo, a pesar de que esencialmente resultan idénticos los pilares del universo moral y del universo jurídico para Kant, hay que dejar constancia de que, en materia de dignidad de la persona humana, no siempre se muestran en sintonía la Fundamentación de la metafísica de las costumbres y la Metafísica de las costumbres, cuestión que merece un estudio más detallado.

Sirve para su análisis la revisión de las bases teóricas del principio de dignidad de la persona humana -y, por consiguiente, de la teoría de los derechos fundamentales -, teniendo por premisa el siempre oportuno reconocimiento de la primacía del ser humano para el universo jurídico. Y es esto lo que pretendemos analizar en las páginas que siguen, prestando especial atención a algunos de los fragmentos de los textos de las dos obras ya citadas, a la vez que nos apoyaremos en referencias realizadas por otros autores contemporáneos en relación al pensamiento kantiano y acerca del concepto de dignidad.

La dignidad de un ser racional consiste en el hecho de que no obedezca a ninguna ley que no sea también instituida por él mismo: “Obra de tal modo que tomes a la

${ }^{14}$ F. González Vicén apunta que hasta Kant, la fuerza vinculatoria del Derecho positivo se había hecho descansar, con algunas pocas excepciones, en la suma de bienes o ventajas que el ordenamiento estatal hacía posibles. En este sentido, "el Derecho positivo queda convertido en un medio al servicio de un fin, y su fuerza de obligar quedaba reducida a lo que Kant denomina "imperativo hipotético", es decir, la paradoja de una regla técnica que nos dice, no qué es deber en absoluto, sino tan sólo qué hemos de hacer "si" queremos lograr algo o llegar a cierto resultado. A esta fundamentación "hipotética” Kant opone una fundamentación “objetivamente necesaria” del Derecho positivo. El Derecho positivo no es algo cuya obligatoriedad depende del logro de un fin que nosotros podamos querer o no, sino que, en tanto que orden cierto e inviolable de la convivencia, es condición para el ejercicio de la libertad trascendental en el mundo sensible y, por tanto, condición de la moralidad; es decir, que el Derecho positivo fundamenta la posibilidad de un fin cuya realización es para nosotros un imperativo absoluto, como predicado que es de nuestro propio ser racional y ético. De esta manera el concepto del Derecho positivo queda inserto en el ámbito del "reino de los fines" y dotado de una justificación ética formal incondicionada” ("Introducción” a la Introducción a la teoría del Derecho, de I. Kant, cit., pp. 24-25).

${ }^{15}$ Cfr. DINIZ, M‥H., Compêndio de introdução à ciência do direito, $7^{a}$ ed., São Paulo, Saraiva, 1995, pp. 39-40. 
humanidad, tanto en tu persona como en la persona de cualquier otro, siempre al mismo tiempo como un fin y no solamente como un medio”. El concepto de dignidad humana deriva de la afirmación primera de Kant de que a la dimensión moral de la persona no se la puede reconocer precio, y que tal premisa teórica tuvo a lo largo del siglo XX primordial importancia para la superación de regímenes totalitarios. Lo que tiene precio puede ser sustituido por alguna otra cosa equivalente; lo que es superior a cualquier precio, y por eso no permite ninguna equivalencia, tiene dignidad. Substancialmente, la dignidad de un ser racional consiste en el hecho de "no obedecer a ninguna ley que no sea también instituida por él mismo. La moralidad, como condición de esa autonomía legislativa es, por tanto, la condición de dignidad del hombre, y la moralidad y la humanidad son las dos únicas cosas que no tiene precio.

La relevancia de la teoría kantiana en orden a la comprensión de lo que actualmente se entiende por dignidad de la persona humana es evidente. Incluso el texto de la Declaración Universal de los Derechos del Hombre constituye un claro reflejo. ${ }^{16}$

Por su voluntad racional, la persona, al mismo tempo que se somete a las leyes de la razón práctica, es la fuente de esas mismas leyes, de ámbito universal, según el imperativo categórico - ‘actúa únicamente según la máxima, por la cual tu puedas querer, al mismo tiempo, que se transforme en ley general'. (...) La esclavitud acabó siendo universalmente abolida, como instituto jurídico, en el siglo XX. Pero la concepción kantiana de dignidad de la persona como un fin en sí lleva a condenar muchas otras prácticas de conversión de la persona en condición de cosa, además de la clásica esclavitud, tales como el engaño de otro mediante falsas promesas, o de atentados cometidos contra los bienes ajenos. Además, añade Kant, si el fin natural de todos los hombres es la realización de su propia felicidad, no basta actuar de modo que no se perjudique a nadie. Esta sería una máxima meramente negativa. Tratar a la humanidad como un fin en sí implica el deber de favorecer, tanto como sea posible, el fin de otro. Siendo el sujeto un fin en sí mismo, es preciso que los fines de otro sean por mí considerados también como míos. ${ }^{17}$ Al tratar acerca de las raíces históricas del principio de la dignidad humana resulta referencia obligada vincularlo al ideario kantiano, principalmente a partir de las nociones de que el ser humano es un ente dotado de autonomía racional y que nunca debe ser considerado como un instrumento para la satisfacción de los intereses de otro.

3. LA DIGNIDAD DE LA PERSONA HUMANA EN LA FUNDAMENTACIÓN DE LA METAFÍSICA DE LAS COSTUMBRES

Kant, en la Fundamentación de la metafísica de las costumbres, se preocupó por demostrar cómo los principios morales, dictados por la razón, deben ser valorados de modo que puedan llegar a asumir el papel de leyes universales. Al mismo tiempo, Kant valoró la vida humana y puso de manifiesto que el ser humano debe ser

${ }^{16}$ En sus Fundamentos de la metafísica (12 ${ }^{\text {a }}$ sección), Kant afirma que el hombre no debe jamás ser utilizado únicamente como medio sin considerar que él es, al mismo tiempo, un fin en sí. La dignidad, tal como resulta definida en la moral kantiana, es el primer derecho fundamental de todo hombre, como proclama el artículo 1 de la Declaración Universal de los Derechos del Hombre de 1948.

${ }^{17}$ KONDER COMPARATO, F., A afirmação histórica dos direitos humanos, 3. ed., São Paulo, Saraiva, 2003, pp. 21-22. 
considerado como un fin en sí mismo, y jamás como un instrumento de sumisión a otro, bajo pena de que sus principios morales no sirvieran como leyes universales: “(...) el imperativo universal del deber también podría rezar así: obra como si la máxima de tu acción fuese a convertirse por tu voluntad en una ley universal de la naturaleza. (...) Uno que, por una serie de males que han crecido hasta la desesperanza, siente fastidio por la vida, está aún lo suficiente en posesión de su razón para poder preguntarse a sí mismo si quitarse la vida no será acaso contrario al deber hacia sí mismo. Prueba por tanto si la máxima de su acción puede quizá convertirse en una ley universal de la naturaleza. Su máxima es: tomo por amor propio como principio acortarme la vida si ésta me amenaza a largo plazo con más mal que agrado me promete. Nos preguntamos aún solamente si este principio del amor propio puede convertirse en una ley universal de la naturaleza. Pero entonces se ve pronto que una naturaleza cuya ley fuese destruir la vida misma por la misma sensación cuyo cometido es impulsar al fomento de la vida contradiría esa sensación misma y, así pues, no susbsistiría como naturaleza, y por tanto es imposible que aquella máxima se dé como ley universal de la naturaleza, y por consiguiente contradice enteramente al principio supremo de todo deber". ${ }^{18}$

Más adelante, Kant reafirma la procedencia del ser humano: “(...) En el supuesto de que hubiese algo cuya existencia en sí misma tuviese un valor absoluto, que como fin en sí mismo pudiese ser un fundamento de determinadas leyes, entonces en eso, y sólo en eso únicamente, residiría el fundamento de un posible imperativo categórico, esto es, de una ley práctica. Pues bien, yo digo: el hombre, y en general todo ser racional, existe como fin en sí mismo, no meramente como medio para el uso a discreción de esta o aquella voluntad, sino que tiene que ser considerado en todas sus acciones, tanto en las dirigidas a sí mismo como también en las dirigidas a otros seres racionales, siempre a la vez como fin". ${ }^{19}$

Después, buscando relacionar la idea de ley moral universal y del ser humano como un fin en sí mismo, Kant enuncia el imperativo práctico que deriva de ahí: "El imperativo práctico será pues el siguiente: obra de tal modo que uses la humanidad tanto en tu persona como en la persona de cualquier otro siempre a la vez como fin, nunca meramente como medio". ${ }^{20}$

Kant también logró acentuar, como hemos mencionado anteriormente, que la conservación de la vida humana es fundamental, y que el hombre debe ser considerado como un fin en sí mismo: “(...) Según el concepto del deber necesario hacia sí mismo, quien está dando vueltas a la idea del suicidio se preguntará si su acción puede compadecerse con la idea de la humanidad como un fin en sí misma. Si, para escapar a un estado penoso, se destruye a sí mismo, se sirve de una persona meramente como un medio para la conservación de un estado soportable hasta el fin de la vida. Pero el hombre no es una cosa, y por tanto no es algo que pueda ser usado meramente como medio, sino que tiene que ser considerado siempre en todas nuestras acciones como

\footnotetext{
${ }^{18}$ KANT, I., Fundamentación de la metafísica de las costumbres, cit., p. 173 (421, 17-21, 422, 1-14).

${ }^{19}$ KANT, I., cit., pp. 185-187 (428, 3-10).

${ }^{20}$ KANT, I., cit., p. 189 (429, 10-14).
} 
fin en sí mismo. Así pues, no puedo disponer del hombre en mi persona para mutilarlo, corromperlo o matarlo"21.

Más adelante, insiste en la idea de ley universal que rechaza la utilización del hombre como medio para otro fin que no sea él mismo: "Los seres racionales están todos bajo la ley de que cada uno de los mismos debe tratarse a sí mismo y a todos los demás nunca meramente como medio, sino siempre a la vez como fin en sí mismo". ${ }^{22}$

Resulta célebre, en el pensamiento de Kant, la conceptuación de dignidad como la cualidad de aquello que no tiene precio y su atribución al ser humano, justamente porque no es un instrumento, sino un fin en sí mismo: "En el reino de los fines todo tiene un precio o una dignidad. En el lugar de lo que tiene un precio puede ser puesta otra cosa equivalente; en cambio, lo que se halla por encima de todo precio, y por tanto no admite nada equivalente, tiene una dignidad. Lo que se refiere a las universales inclinaciones y necesidades humanas tiene un precio de mercado; lo que, también sin presuponer necesidades, es conforme a cierto gusto, esto es, a una complacencia en el mero juego, sin fin alguno, de nuestras facultades anímicas tiene un precio afectivo; pero aquello que constituye la condición únicamente bajo la cual algo puede ser fin en sí mismo no tiene meramente un valor relativo, esto es, un precio, sino un valor interior, esto es, dignidad" ${ }^{23}$

Especificando aún más el concepto de dignidad humana, Kant la equipara a la autonomía de su actitud racional para elegir los principios morales que puedan servir como leyes universales: "La autonomía es, así pues, el fundamento de la dignidad de la naturaleza humana y de toda la naturaleza racional”. ${ }^{24}$

Kant subraya que tal prerrogativa del ser humano racional en el sentido de ser "legislador universal” no lo exime de someterse a esta misma legislación: “(...) y la dignidad de la humanidad consiste precisamente en esta capacidad de ser universalmente legisladora, aunque con la condición de estar ella misma a la vez sometida precisamente a esta legislación”. ${ }^{25}$

En definitiva, en la Fundamentación de la metafísica de las costumbres, Kant pretendió demostrar que la dignidad de la persona humana sería el resultado de la conjunción de la autonomía del ente racional para la formulación de principios morales universales, con el hecho de que el ser humano no tiene precio, y de que debe existir en cuanto fin en sí mismo y jamás como instrumento para la satisfacción de los intereses de otro ${ }^{26}$.

${ }^{21}$ KANT, I., cit., p. 189 (429, 15-25).

${ }^{22}$ KANT, I., cit., p. 197 (433, 27-30).

${ }^{23}$ KANT, I., cit., pp. 201-203 (434, 33-38, 435, 1-4).

${ }^{24}$ KANT, I., cit., p. 203 (436, 6-8).

${ }^{25}$ KANT, I., cit, p. 211 (440, 11-14).

${ }^{26}$ Como apunta G. Peces-Barba, "La concepción formal de Kant, que basa la dignidad en la autonomía como postulado de la razón, tiene el gran valor de conectar dignidad, libertad, autonomía y moralidad, edificio que desde entonces se mantendrá como explicación básica de esta dignidad humana”. Y más adelante subraya: "La dignidad humana se formula desde dos perspectivas (...) una más formal de raíz kantiana y otra más de contenidos, de carácter humanista y renacentista. Por la primera, la dignidad deriva de nuestra decisión de mostrar capacidad de elegir, de nuestra autonomía; por la segunda, la dignidad consiste en el estudio de los rasgos que nos diferencian de los restantes animales. Son dos perspectivas complementarias, casi podríamos decir la forma y el contenido de nuestro valor como personas” (op. cit., p. 56 y p. 65). 


\section{LA DIGNIDAD DE LA PERSONA EN LA METAFÍSICA DE LAS COSTUMBRES. ALGUNAS CONTRADICCIONES CON LA FUNDAMENTACIÓN DE LA METAFÍSICA DE LAS COSTUMBRES}

En la primera parte de la Metafísica de las costumbres, conocida como Doctrina del Derecho, Kant realiza unos raciocinios que se muestran aparentemente discrepantes con el principio de dignidad humana antes enunciado en la Fundamentación de la metafísica de las costumbres. Si en la obra anterior la preocupación de Kant fue la de elaborar conceptos de filosofía moral, en esta nueva obra el filósofo alemán trata conceptos de filosofía jurídica.

En cualquier caso, en materia de derecho, Kant casi siempre se refiere al ser humano en la condición de titular de derechos patrimoniales (derechos reales y personales) y en sus relaciones familiares y con sus empleados. Es lo que hoy podríamos entender como una teoría general de los derechos de la personalidad, entre los que Kant se limitó a tratar del derecho de libertad.

La parte que ha sido objeto de principal atención por nuestra parte ha sido la de la doctrina de la propiedad. Como apunta A. Cortina, en el Estudio preliminar de la obra ya citada, en principio Kant entiende, como Fichte, que la verdadera posesión no es la de las cosas, sino la del uso de las cosas: poseer una cosa significa estar facultado para usarla. Pero en segundo lugar, esta facultad no se adquiere gracias al trabajo invertido en ella ni al intento de configurarla -como antes había sostenido J. Locke-, sino que se adquiere por ocupación. La ocupación será condición de la posesión legítima ${ }^{27}$. No vamos a entrar en el análisis de la potestad dominativa conjunto de poderes que intervienen en las relaciones humanas que se desarrollan en el ámbito doméstico- de Kant. Vamos a limitarnos a exponer brevemente el poder doméstico que presentaba Kant, es decir, el vínculo de sujeción entre el jefe de la casa y los demás miembros de la misma, ya se trate de la esposa, de los hijos o de la servidumbre. Lo analizaremos en relación a su concepto de libertad y, sobre todo, al de dignidad de la persona humana. Destacaremos cómo se aprecia una contradicción en su teoría cuando sostiene la posibilidad de reducir a algunos individuos a cosas, en el tema de la propiedad.

Para entender adecuadamente su línea de pensamiento, conviene que transcribamos algunos fragmentos de su obra, que nos servirán muy bien de ejemplo para exponer nuestras ideas.

En primer lugar, a efectos de transposición de la idea de libertad que impregna su filosofía moral, Kant enuncia como principio universal del derecho la siguiente afirmación: "Una acción es conforme a derecho (Recht) cuando permite, o cuya

${ }^{27}$ Continúa A. Cortina: "Naturalmente esta tesis ha suscitado duras críticas en el ámbito de la filosofía jurídica y política, en la medida en que Kant parece olvidar las exigencias de la razón en los puntos más delicados y plegarse a los hechos. Porque si en la doctrina del derecho político es la toma del poder la que legitima en definitiva a un determinado gobernante, en el caso del derecho privado parece que sea el hecho de la ocupación el que legitima la posesión (...) Limitándonos por el momento al derecho privado, creemos que la acusación es injusta porque la ocupación es uno de los momentos de la adquisición, pero no el único. Otros dos momentos son necesarios: la declaración del sujeto de que toma posesión del objeto y la apropiación como acto de la voluntad universalmente legisladora” (op. cit., p. XLVII). 
máxima permite a la libertad del arbitrio de cada uno coexistir con la libertad de todos según una ley universal”. ${ }^{28}$

Kant buscó, por consiguiente, conciliar, en el plano jurídico, la libertad de cada uno con la libertad de todos. He aquí la argumentación de Kant: "El Derecho estricto puede representarse también como la posibilidad de una coacción recíproca universal, concordante con la libertad de cada uno según leyes universales. Esta proposición significa lo siguiente: el derecho no puede pensarse como compuesto por dos elementos, es decir, de la obligación según una ley y de la facultad de aquel que obliga a los otros por su arbitrio de coaccionarles a ello, sino que podemos establecer inmediatamente el concepto de derecho sobre la posibilidad de conectar la coacción recíproca universal con la libertad de cada uno. Así como el derecho en general sólo tiene por objeto lo que es exterior en las acciones, el derecho estricto, es decir, aquel que no está mezclado con nada ético, es el que no exige sino fundamentos externos de determinación del arbitrio; porque entonces es puro y no está mezclado con prescripciones referidas a la virtud. Por tanto, sólo puede llamarse derecho estricto (restringido) al derecho completamente externo". ${ }^{29}$

En lo que concierne a la existencia de un derecho natural o innato, Kant reconoce uno, consistente en la libertad, y que enuncia así: "No hay sino un derecho innato. La libertad (la independencia con respecto al arbitrio constrictivo de otro), en la medida en que puede coexistir con la libertad de cualquier otro según una ley universal, es este derecho único, originario, que corresponde a todo hombre en virtud de su humanidad. -La igualdad innata, es decir, la independencia, que consiste en no ser obligado por otros sino a aquello a lo que también recíprocamente podemos obligarles; por consiguiente, la cualidad del hombre de ser su propio señor (sui iuris); (...). ${ }^{30}$

En relación a lo que denominaba "Derecho Privado", Kant formula unas propuestas que se revelan incompatibles con la idea de dignidad de la persona humana que se tiene actualmente, en la medida en que admitía que algunos seres humanos podían ser objeto de tal dominación: "Yo puedo llamar míos a una mujer, un niño, un siervo y, en general, cualquier otra persona, no porque yo los gobierne ahora como pertenecientes a mi casa, o los tenga bajo mi control, en mi potestad y posesión, sino, aunque se hayan sustraído a mi coerción y, por tanto, no los posea (empíricamente), sí puedo decir, sin embargo, que los poseo por mi simple voluntad mientras existan en cualquier sitio y en cualquier momento, por tanto, de modo meramente jurídico; de ahí que pertenezcan a mi haber sólo si y en la medida en que puedo afirmar lo último". ${ }^{31}$

Más adelante, Kant reafirma la posibilidad de que las personas sean objeto de posesión jurídica ejercida por otra persona: "Lo mismo ocurre también con el concepto de la posesión jurídica de una persona, como perteneciente al haber del sujeto

${ }^{28}$ KANT, I., Metafísica de las costumbres, cit., p. 39 (230).

${ }^{29}$ KANT, I., cit., p. 41 (232)

${ }^{30}$ KANT, I., cit., pp. 48-49 (237).

${ }^{31}$ KANT, I., cit., p. 59 (248). 
(su mujer, su hijo, su criado): que esta comunidad doméstica y la posesión recíproca del estado de todos sus miembros no se eliminan por la capacidad de separarse localmente unos de otros; porque lo que los une es una relación jurídica, y lo mío y lo tuyo exterior aquí, como en los casos anteriores, se apoya totalmente en la presuposición de la posibilidad de una posesión racional pura sin tenencia”. ${ }^{32}$

Kant continua presentando las personas como cosas, al tratar de la caracterización del derecho mixto que resulta de la combinación del derecho real con el derecho personal, con vistas a la adquisición de objetos: “(...) la adquisición es triple según el objeto: el varón adquiere una mujer, la pareja adquiere hijos y la familia, criados. Todo esto que puede adquirirse es a la vez inalienable y el derecho del poseedor de estos objetos es el más personal de todos". ${ }^{33}$

En relación al derecho doméstico, y en particular del matrimonio, Kant llega a admitir expresamente que hombre y mujer pueden ser considerados como cosas. En cualquier caso, al verificar la posibilidad de equiparación de personas y cosas, Kant trata inmediatamente de apartarse del absurdo que tal concepción podría representar, en la medida de la reciprocidad del débito conyugal, lo que daría lugar a que la personalidad inherente al hombre fuera limitada en la propia relación. Es lo que se deduce de sus reflexiones acerca del débito conyugal: "En efecto, el uso natural que hace un sexo de los órganos sexuales del otro es un goce, con vistas al cual una parte se entrega a la otra. En este acto un hombre se convierte a sí mismo en cosa, lo cual contradice al derecho de la humanidad en su propia persona. Esto es sólo posible con la condición de que, al ser adquirida una persona por otra como cosa, aquella, por su parte, adquiera a ésta recíprocamente; porque así se recupera a sí misma de nuevo y reconstruye su personalidad. Pero la adquisición de un miembro del cuerpo de un hombre es a la vez adquisición de la persona entera, porque ésta es una unidad absoluta; por consiguiente, la entrega y la aceptación de un sexo para goce del otro no sólo es lícita con la condición del matrimonio, sino que sólo es posible con esta condición. Ahora bien, el hecho de que este derecho personal sea también de índole real (dingich) se funda en que, si uno de los cónyuges se ha separado o se ha entregado en posesión a otro, el otro está legitimado, siempre e incontestablemente a restituirlo en su poder, igual que una cosa”. ${ }^{34}$

Cuando se ocupa de los derechos del amo (patrón) sobre sus criados, Kant deja claro que se trata de la relación en la que una de las partes -el criado- por medio del contrato, da su libertad -y, por consiguiente, limita su condición de persona -, para someterse a la dominación de otra (patrón): “(...) La servidumbre pertenece entonces a lo suyo del dueño de la casa (...) porque sólo están en su poder por contrato, pero es en sí mismo contradictorio -es decir, nulo e inválido- un contrato por el que una parte renuncia a su entera libertad en beneficio del otro, por tanto, deja de ser persona (...)".35

Conviene destacar, también, que el filósofo alemán acentúa en sus estudios el

${ }^{32}$ KANT, I, cit., pp. 67-68 (254).

${ }^{33}$ KANT, I., cit., p. 97 (267).

${ }^{34}$ KANT, I., cit., pp. 98-99 (278).

${ }^{35}$ KANT, I., cit., p. 105 (283). 
carácter real (incluso en parte) de los contratos que rigen tales relaciones, incluso aunque tengan por objeto la prestación de servicios por parte de un ser humano, como si este pudiera ser tratado como cosa y, por lo tanto, susceptible, por ejemplo, de reivindicación: “(...) hay un derecho personal de índole real (auf dingliche Art) (del dueño sobre los siervos): porque se les puede recuperar y reclamar como lo suyo exterior de cada poseedor (...)". 36

En suma, al tratar, en una perspectiva jurídica, acerca de los derechos que se pueden reconocer a la persona, Kant señala la premisa de la libertad y, seguidamente, afirma que el ser humano puede ser tratado como cosa, tal como sucede con aquéllos que están bajo la dominación del poder del dueño de la casa o del patriarca de la familia, es decir, las esposas, los hijos y los criados, en una relación de derecho también real. Al afirmar, pues, que el hombre puede ser jurídicamente tomado como cosa, Kant, al menos a los ojos del lector actual, entra en contradicción con la afirmación de que el ser humano debe ser siempre considerado como un fin, y jamás como un medio.

Existe, por lo tanto, una nítida distancia -por no decir incompatibilidad- entre la enunciación teórica de la dignidad de la persona humana en Kant y su aplicación en el campo del derecho.

5. CONVENIENCIA DE UNA RELECTURA CRÍTICA DEL PENSAMIENTO DE KANT ACERCA DE LA DIGNIDAD DE LA PERSONA HUMANA

Como hemos podido observar, la doctrina actual de los derechos fundamentales, al tratar del principio de dignidad de la persona humana, atribuye a Kant su concepción original. Hemos visto también que Kant, al mismo tiempo que, desde la perspectiva de la filosofía moral, ha procurado sustentar como fundamental la noción de dignidad de la persona humana -como consecuencia de su libertad racional, así como de su existencia en cuanto fin y nunca como medio-, ha tratado al ser humano como cosa desde la perspectiva jurídica, al tratar acerca de la condición de aquéllos que se sometían al marido, al padre y al patrón. Además, también hemos destacado cómo la doctrina actual, como consecuencia de la evolución de las generaciones de derechos fundamentales, vincula la noción de dignidad de la persona humana a la inviabilidad de tratar al ser humano como cosa.

Resulta así evidente la insuficiencia de la mera noción de libertad racional propuesta por Kant para la plena fundamentación del principio de dignidad, sin contar la clara incompatibilidad entre los preceptos jurídicos enunciados por Kant y la idea de que el ser humano no puede ser tratado como medio u objeto.

El universo temporal y espacial kantiano influyeron en su modo de pensar. Kant se nos presenta como un buen pensador impregnado de los idearios liberales de su época, que pretendían la protección del individuo contra los excesos de las monarquías absolutistas. Así, las ideas de libertad y de valorización de cada ser humano individualmente se adaptaron muy bien a la noción de autonomía racional de la persona,

${ }^{36}$ KANT, I., cit., p. 106 (284). 
desembocando en la construcción de conceptos jurídicos que pudieran, desde el punto de vista privado, satisfacer las necesidades de cada uno individualmente. ${ }^{37}$

Tal vez haya sido suficiente para Kant, consagrar la noción meramente teórica de que el ser humano está dotado de autonomía racional, y partiendo de ahí, con la protección estatal mediante la fuerza de la coerción de que está dotado el derecho, la posibilidad de la convivencia pacífica en sociedad, a pesar de que esto implicara, en la práctica y en algunas hipótesis, el tratamiento del ser humano como $\cos ^{38}$.

En cualquier caso, en la medida en que superemos el universo temporal en que vivió Kant, resulta posible concluir que la utilización de sus preceptos teóricos para la fundamentación de la noción de dignidad de la persona humana en la actualidad debe realizarse con las debidas reservas.

Si es verdadera la afirmación de que la noción de Kant acerca de la autonomía racional del ser humano sirve como uno de los fundamentos del principio de dignidad humana -y, por consiguiente, a la teoría de los derechos fundamentales-, no es menos verdadera la conclusión en el sentido de que su concreción en la actualidad se debe limitar, ya que resulta inadmisible, en la práctica, que el ser humano trate a su semejante como una cosa.

\section{EL PRINCIPIO DE DIGNIDAD DE LA PERSONA HUMANA Y SU CONCRECIÓN SEGÚN LA DOCTRINA ACTUAL}

6.1. A pesar de que no pueda negarse, como hemos visto anteriormente, que el principio de dignidad de la persona humana puede tener algunas de sus raíces históricas en el pensamiento de Kant, conviene destacar que la noción que se tiene actualmente de la dignidad supera la afirmación de la mera libertad racional.

Comprender en nuestros días qué es el principio de dignidad de la persona humana significa tener como premisa que el ser humano, como fin de todo, es un ente real cuyas necesidades mínimas concretas no pueden estar sujetas a los modelos

\footnotetext{
${ }^{37}$ Claudio de Cicco, en el prefacio de la traducción de la Doutrina do Direito -primera parte de la Metafísica de las costumbres- en la edición en portugués, establece el marco circunstancial del pensamiento de Kant a partir de las referidas condiciones y pone de manifiesto sus objetivos: “(...) el principio de libertad no podría valer sólo para algunos, pues entonces no sería un 'principio' sino una regla de solución del casuismo. Esto significa que debe valer para todos, todos deben gozar de libertad, de lo que resulta un postulado igualitario. Entretanto, la igualdad preconizada por Kant, garantizada por el Estado y por el Derecho, tanto como la libertad, es la igualdad de oportunidad, la igualdad en el punto de partida, todos tiene derecho a lo básico (actualmente enumeraríamos vivienda, salud, educación, trabajo, alimentación), pero queda el progreso de cada uno dependiendo de su esfuerzo y dinamismo, lo que distancia a Kant de todos aquéllos que pretenden una igualdad permanente” (Cfr. CICCO, C. (de), Prefacio a Doutrina do direito de I. Kant, trad. E. Bini, Sâo Paolo, Ícone, 1993, p. 9).

38 J. L. Pérez Triviño, en relación al examen de la concepción kantiana de la dignidad, concluye estableciendo tres puntos de referencia: “1) La dignidad humana es una propiedad de todo ser humano, es el producto de un cierto tipo de abstracción de los rasgos peculiares y contingentes de los humanos. Por esta razón, la dignidad kantiana se fundamenta no en los seres humanos de carne y hueso, sino en una concepción noumenal, esto es, una concepción abstracta de los individuos, y no una concepción realista y descriptiva de cómo son estos; 2) La dignidad es independiente de las emociones, lo cual significa que el respeto que se debe a un individuo (o el propio autorrespeto) está al margen de cual sea la impresión o percepción del propio individuo; 3) La dignidad está vinculada con la igualdad básica de todos los seres humanos” (op. cit., p. 73).
} 
abstractos tradicionales: En primer lugar, la dignidad de la persona es de la persona concreta, en su vida real y cotidiana; no es de un ser ideal y abstracto. Es el hombre o la mujer, tal como existen, a los que el orden jurídico considera irreductible e insustituible y cuyos derechos fundamentales enuncia y protege la Constitución. En todo hombre y en toda mujer están presentes todas las facultades de la humanidad.

En cuanto a la concreción del principio de dignidad de la persona humana, merece especial atención la cuestión de la reducción del hombre a la condición análoga de esclavo en materia de relaciones de trabajo. Ciertamente, no se puede hablar de dignidad de la persona si esto no se materializa en sus propias condiciones de vida. ¿Cómo hablar de dignidad sin derecho a la salud, al trabajo, en fin, sin derecho de participar en la vida en sociedad con un mínimo de condiciones? Tener trabajo, y en condiciones dignas, es una forma de proporcionar al hombre los derechos que derivan de ese atributo que le es propio: la dignidad. Como apunta la OIT, 'El control abusivo de un ser humano sobre otro es la antítesis del trabajo digno'. ${ }^{39}$

Resulta evidente que, cuando Kant escribió la Fundamentación para una metafísica de las Costumbres, no era consciente de que algún día serían utilizadas para solucionar las disputas filosóficas que copan actualmente buena parte del debate bioético. Kant no se llegó a plantear cuestiones tales como la de si un débil mental era menos digno que otra persona. Sin embargo, el auge de la biotecnología nos ha obligado a encarar estas complejas preguntas ${ }^{40}$.

Por ejemplo, en el caso de la clonación de seres humanos, el precepto kantiano de que el ser humano jamás debe ser considerado como cosa, nos puede hacer pensar en la conveniencia de actualizar la noción de dignidad de la persona: ¿Qué pensar de todo eso, a la luz del principio supremo del respeto a la dignidad humana en cualquier circunstancia? En teoría, la única práctica aceptable, en una perspectiva ética, parece ser la de la clonación humana para fines terapéuticos (por ejemplo, tratamiento de enfermedades neurodegenarativas, como el mal de Parkinson, o el Alzheimer), en el propio sujeto cuyas células fueran clonadas. Todas las otras prácticas de fecundación artificial o de ingeniería genética violan- -en opinión de algunos autores-, el principio kantiano de que la persona humana no puede ser nunca utilizada como simple medio para la obtención de una finalidad ajena, pues ella debe ser considerada siempre como un fin en sí misma.

También en aquellas situaciones, cada vez más comunes, en que los padres conciban a un nuevo hijo para poder solucionar problemas degenerativos de otro hijo ya nacido y que, sin el transplante o el apoyo de algún órgano vital de su hermano que garantiza la compatibilidad- morirá. Generalmente se realiza una selección de embriones en laboratorio previamente, al objeto de rechazar los que puedan estar

\footnotetext{
${ }^{39}$ MONTEIRO DE BRITO FILHO, J.C., "Trabalho com redução do homem à condição análoga a de escravo e dignidade da pessoa humana”, en http://www.pgt.mpt.gov.br/publicacoes/escravo.html, pp. 7-8, acceso el 6 de junio de 2005.

${ }^{40}$ Cfr. MIGUEL BERIAIN, I. de, “¿Es digno un ser que no es autónomo? Reflexiones acerca del concepto kantiano de dignidad humana”, en Estudios en Homenaje al Profesor Gregorio Peces-Barba. Vol. III. Teoría de la Justicia y Derechos Fundamentales. Madrid, Insitito de Derechos Humanos Bartolomé de las Casas-Dykinson- Santander, 2008, pp. 415-429.
} 
dañados de la misma enfermedad genética o degenerativa. Y se aprovecha un embrión en buen estado, que garantice más posibilidades de éxito. ¿No es este un caso claro de utilización de una vida -la del hijo que se selecciona- como medio y no como un fin en sí mismo? Los padres no dan la vida al segundo hijo por amor en sí mismo a esa nueva vida sino que lo utilizan como instrumento, como medio, para salvar la vida de su primer hijo. ¿Dónde queda la dignidad del segundo hijo?

Hoy en día, por tanto, dada la evolución de la teoría de los derechos fundamentales, no sería posible convivir con la discrepancia entre la Fundamentación de la metafísica de las costumbres y la Metafísica de las costumbres de Kant en lo que se refiere a la dominación del hombre por el hombre, como si se pudiera inserir el elemento humano en el espacio destinado a las cosas en las relaciones jurídicas, y como si fuera suficiente con valorar apenas la noción de autonomía racional del ser humano.

En definitiva, la relación entre dominio y propiedad en Kant, heredero de las doctrinas de filósofos y juristas relevantes anteriores, puede resultar discutible y controvertida en nuestros días. Si nos remitimos a su concepto de dignidad y a su defensa de la libertad, de la moral y otros muchos conceptos, podemos apreciar que “chirrían” al ponerlos en relación con la potestad dominativa en el ámbito de la familia. Cierto que resulta innegable su contribución en orden a configurar las bases del principio de dignidad de la persona, pero se hace necesaria una actualización de su significado en orden a su adscripción al marco de un Estado social y democrático de derecho, que se asienta en los pilares de la libertad y de la igualdad.

6.2. En cierta forma, la vaguedad del concepto de dignidad de la persona acaba remitiendo a una concreción en el marco de un debate abierto a consideraciones morales. Cabe pues preguntarse si la dignidad de la persona es más un concepto de tintes jurídicos o de tintes morales. Su incorporación a textos jurídicos ha sido tardía y, sin embargo, a lo largo de la historia, ha sido un sustrato permanente a las construcciones que se iban formulando. G. Peces-Barba ha apuntado que "la dignidad humana tiene un puesto relevante aunque prepolítico y prejurídico” (...) no es contenido del derecho (...) más bien una construcción de la filosofía (...) un deber ser fundante (...) aunque muchas veces sea referencia en las argumentaciones o en la interpretación jurídica, ${ }^{41}$.

El reflejo jurídico del principio de dignidad de la persona humana ha sido muy tardío. Hasta después de la segunda guerra mundial no se apreció la necesidad de que constara como tal en un texto jurídico. A partir de ahí, resulta común encontrarla en los textos de derechos humanos y Constituciones: textos de Naciones Unidas, Constitución española, jurisprudencia del Tribunal Constitucional español, Carta de los derechos fundamentales de la Constitución europea, etc.

Concretamente, en el ámbito internacional, se puede encontrar: en la Declaración Universal de 1948, que la recoge en el preámbulo y en el artículo primero donde se la vincula a la libertad y a la igualdad ${ }^{42}$. También en el Pacto de Derechos Civiles y

${ }^{41}$ PECES-BARBA MARTÍNEZ, G., op. cit., p. 64 ss.

${ }^{42}$ El preámbulo dice así: "Considerando que la libertad, la justicia y la paz en el mundo tienen por base el reconocimiento de la dignidad intrínseca y de los derechos iguales e inalienables de todos los miembros de 
Políticos de 1966, señalando en su preámbulo que los derechos derivan de la dignidad inherente a la persona humana. Asimismo, hay una referencia en el preámbulo del Pacto internacional de Derechos económicos, sociales y culturales, también de 1966.

La Constitución española de 1978 proclama, en su artículo 10.1, que: "la dignidad de la persona, los derechos que le son inherentes, el libre desarrollo de la personalidad, el respeto a la ley y a los derechos de los demás son fundamento del orden político y de la paz social”. Esta caracterización de la dignidad como "fundamento" del orden político y de la paz social, y no como "valor superior" ni como "principio" ha dado lugar a ciertos problemas semánticos y conceptuales. Es más, hay opiniones que sostienen que la dignidad de la persona ha sido devaluada en nuestra Constitución, defendiendo que su correcta ubicación -como fundamento ontológico de los demás valores- hubiera correspondido al artículo 1.1 en el que se "propugnan los valores superiores del ordenamiento jurídico. La libertad, la justicia, la igualdad y el pluralismo son exigencias derivadas de la dignidad de la persona, siendo la dignidad el valor de los valores.

No estamos ante un derecho fundamental con existencia autónoma que se produzca al margen de "los derechos de esta índole expresamente previstos en la Constitución”"43. Tampoco hay que confundir su vinculación con derechos fundamentales determinados con la afirmación de que esos derechos constituyan propiamente el contenido de la dignidad. Algunos autores entienden que el contenido de la dignidad de la persona incluye la igualdad, la protección de la identidad y la integridad física y moral. Y, según la fórmula del Estado social y democrático de Derecho, debería incluir también la garantía del mínimo vital de subsistencia. Otros autores, como López Pina, evocando a Kant, han entendido que debería integrar la libertad, igualdad, seguridad y autodeterminación política en un paradigma de relaciones entre Estado y sociedad en el que los derechos fundamentales desempeñan un papel crucial ${ }^{44}$.

Así, aunque la dignidad de la persona no sea un derecho fundamental, de algún modo ha de determinarse su alcance, incluso a pesar de que, como apunta la doctrina española, como "cualidad del ser humano (...) no posee un contenido predeterminado ni vinculado a valores o creencias concretas" o que "la dignidad de la persona es un concepto jurídico indeterminado (...) de muy difícil, por no decir imposible, determinación"

De ahí que algún sector de la doctrina apunte que "se puede afirmar paradójicamente que si no resulta posible determinar en qué consiste ésta, sí que es posible fijar, por el contrario, cuando se vulnera su contenido”. Es por eso que, en ciertas ocasiones la dignidad ha operado, de manera excepcional, de modo equivalente a un derecho fundamental. Es más, para algunos autores, la dignidad opera como fundamento del ordenamiento jurídico, como principio general del derecho, como

la familia humana”; y el artículo primero proclama: "Todos los seres humanos nacen libres e iguales en dignidad y derechos $(. .$.$) ".$

${ }^{43}$ MARÍN CASTÁN, Ma. L., op. cit., p. 6.

${ }^{44}$ GUTIÉRREZ GUTIÉRREZ, I., Dignidad de la persona y derechos fundamentales, Madrid-Barcelona, Marcial Pons, 2005, p. 75.

${ }^{45}$ GUTIÉRREZ GUTIÉRREZ, I., op. cit., p. 93. 
criterio orientador de la interpretación del derecho, como instrumento para la integración del ordenamiento y como norma de conducta y límite en el ejercicio de los derechos.

El legislador constitucional no consideró oportuno que el principio de dignidad tuviera la protección amplia de la que gozan los derechos que pueden ser sujetos del amparo ante el Tribunal Constitucional. Ello implica que no es posible fundar un recurso de amparo en la violación de la dignidad humana. Hay que advertir que aunque no goce de la protección del amparo, es un principio informador del ordenamiento jurídico, lo cual supone que cualquier norma o acto que se le oponga puede ser declarado inconstitucional. La jurisprudencia constitucional ha referido a la dignidad de la persona los derechos fundamentales en su conjunto, como derechos inviolables que le son inherentes. Lo cierto es que los derechos inviolables, como parte del ordenamiento jurídico, han de resultar de los valores superiores: no sólo de la libertad y la igualdad sino también de la justicia y del pluralismo político. Se establece así un apoyo para una concepción integral y dinámica del contenido de la dignidad $^{46}$. Con todo, y conforme dice la STC 120/1990, el artículo 10.1 CE "no significa ni que todo derecho le sea inherente -y por ello inviolable- ni que los que se califican de fundamentales sean in toto condiciones imprescindibles para su efectiva incolumidad, de modo que a cualquier restricción que a su ejercicio se imponga devenga un estado de indignidad" ${ }^{, 47}$.

Por último, en relación al Derecho europeo, hay que apuntar que en el Convenio Europeo de 1950, elaborado y aprobado en el contexto del Consejo de Europa, no hay una referencia concreta a la idea de dignidad ni aparece recogida como tal en un precepto concreto. Sólo indirectamente mediante la remisión expresa a la Declaración Universal, contenida en su preámbulo. Sin detenernos en los diversos textos de ámbito regional europeo, llegamos a la proclamación de la Carta de derechos fundamentales de la Unión Europea, aprobada en la cumbre de Niza en diciembre de 2000. Su artículo se abría con la afirmación: "La dignidad humana es inviolable. Será respetada y protegida”,48.

${ }^{46}$ I. Gutiérrez Gutiérrez apunta que por parte del Tribunal Constitucional ${ }^{46}$ parece haberse adoptado en ocasiones diversas versiones de la fórmula alemana de no-instrumentalización (inspirada en la fórmula kantiana). De ellas extrae el Tribunal Constitucional consecuencias en ámbitos diversos, pero que tienen una coherencia interna evidente:

-La persona no puede ser patrimonializada; es sujeto, no objeto de contratos patrimoniales (STC 212/1996).

-El trabajador no puede ver subordinada su libertad mediante su consideración como "mero factor de producción” o “mera fuerza de trabajo" (STC 192/2003).

-La persona no puede ser, en cuanto tal, mero instrumento de diversión y entretenimiento (STC 231/1988).

- En el mismo sentido, la persona es convertida en mero objeto en los casos de agresión o acoso sexual (SSTC 53/1985 y 224/1999).

- La dignidad impone que la asunción de compromisos u obligaciones tenga en cuenta la voluntad del sujeto, al menos cuando son de peculiar trascendencia, como la maternidad (STC 53/1985).

- Del mismo modo, la dignidad impone que sea reconocida al sujeto la posibilidad de participar en procesos judiciales en los que se atribuyen al sujeto graves responsabilidades penales, sin que pueda aparecer como mero objeto de dichos procedimientos (STC 91/2000).

${ }^{47}$ Cfr. GUTIÉRREZ GUTIÉREZ, I., op. cit., p. 98.

${ }^{48}$ También en su preámbulo: "Consciente de su patrimonio espiritual y moral, la Unión está fundada sobre los valores individuales y universales de la dignidad humana, la libertad, la igualdad y la solidaridad (...) 
Esta Carta de derechos fundamentales se incorporó al Tratado por el que se instituye una Constitución para Europa, cuyo texto se culminó con la firma en Roma el 29 de octubre de 2004. No vamos a ocuparnos ahora de las vicisitudes del texto en relación a su aprobación por los veinticinco países de la Unión Europea. Nos limitamos a destacar que en su artículo I.9 subraya que "La Unión reconoce los derechos, libertades y principios enunciados en la Carta de Derechos fundamentales de la Unión Europea, que constituye la parte II”. Además, en esta Constitución Europea hay un reconocimiento expreso de la dignidad, en el artículo I.2: "La Unión se fundamenta en los valores de respeto de la dignidad humana (como valor primordial y básico), libertad, democracia, igualdad, Estado de Derecho y respeto de los derechos humanos, incluidos los derechos pertenecientes a las minorías. Estos valores son comunes a los Estados miembros en una sociedad caracterizada por el pluralismo, la no discriminación, la tolerancia, la justicia, la solidaridad y la igualdad entre hombres y mujeres".

En definitiva, el tema de la dignidad humana no está cerrado sino que continúa perfilándose al compás de la propia evolución de la sociedad y de las nuevas exigencias a las que el Derecho y la Ética deben ir dando respuesta adecuada.

$\mathrm{Al}$ instituir la ciudadanía de la Unión y crear un espacio de libertad, seguridad y justicia, sitúa a la persona en el centro de su actuación. El primer capítulo de la Carta, dedicado a la dignidad, consta a su vez, de cinco artículos, referentes a la dignidad en general (art. 1), al derecho a la vida (art. 2), a la integridad de la persona (art. 3), a la prohibición de la tortura y de las penas o los tratos inhumanos o degradantes (art. 4) y a la esclavitud o trabajo forzado (art. 5). 